\title{
CORRECTION
}

\section{Correction to: Why Naunyn-Schmiedeberg's Archives of Pharmacology abandons traditional names of drug classes}

\author{
Roland Seifert $^{1} \cdot$ Bastian Schirmer $^{1}$
}

Published online: 20 July 2021

○) Springer-Verlag GmbH Germany, part of Springer Nature 2021

Correction to: Naunyn-Schmiedeberg's Archives of Pharmacology (2021) 394:1321-1325

https://doi.org/10.1007/s00210-021-02111-4

The original version of this article contained some mistakes in Table 1.

This is being corrected in this publication.

Publisher's note Springer Nature remains neutral with regard to jurisdictional claims in published maps and institutional affiliations.

The original article can be found online at https://doi.org/10.1007/ s00210-021-02111-4.

Roland Seifert

seifert.roland@mh-hannover.de

1 Institute of Pharmacology, Hannover Medical School,

Carl-Neuberg-Str. 1, 30625 Hannover, Germany 